\title{
A Unique Isolate of Malassezia from a Cat
}

\author{
Asuka HIRAI ${ }^{1)}$, Rui KANO ${ }^{1)}$, Koichi MAKIMURA ${ }^{2)}$, Kazuo YASUDA ${ }^{3)}$, Kazuyo KONISHI ${ }^{4)}$, Hideo YAMAGUCHI ${ }^{2)}$ \\ and Atsuhiko HASEGAWA ${ }^{1)}$ \\ ${ }^{1)}$ Department of Pathobiology, Nihon University School of Veterinary Medicine, Kameino, Fujisawa, Kanagawa 252-8510, ${ }^{2)}$ Teikyo \\ University Institute of Medical Mycology, Otsuka, Hachioji, Tokyo 192-0395, ${ }^{3)}$ Yasuda Animal Hospital, Naruo, Nishinomiya, Hyogo \\ 663-8177 and ${ }^{4)}$ Research Laboratories, Animal Science Division, Dainippon Pharmaceutical Co., Ltd., Fushio, Ikeda, Osaka 563-0011, \\ Japan
}

(Received 28 January 2002/Accepted 8 July 2002)

ABSTRACT. An isolate of Malassezia from a cat with otitis externa was examined mycologically as well as molecularly. The isolate was similar to M. sympodialis in morphological and biochemical characteristics. In molecular analysis, however, it differed from the 7 species of Malassezia previously reported. Therefore, this clinical isolate from a cat might be a new species of Malassezia. KEY WORDS: feline, Malassezia, molecular analysis.

J. Vet. Med. Sci. 64(10): 957-959, 2002

Malassezia species are recognized as members of microbiological flora of human and animal skin. Malassezia species are also etiological agents of pityriaris versicolor and Malassezia folliculitis in humans and otitis externa in animals [5]. M. pachydermatis and M. sympodialis have been isolated from otitis externa of cats $[4,8]$.

Malassezia species are identified by morphological, biochemical and molecular characteristics $[9,10,16]$. Molecular typings are applied to these species and sequences of the ribosomal internal transcribed spacer 1 (ITS1) region located between $18 \mathrm{~S}$ and $5.8 \mathrm{~S}$ ribosomal DNA and the 5' end of large-subunit (26S) ribosomal DNA (D1/D2 region) have been utilized for the identification of Malassezia species $[6,13]$. In our previous study, we sequenced and analyzed the chitin synthase 2 ( $C H S 2$ ) gene of the 7 recognized species of Malassezia in order to uncover their phylogenetic relationships $[1,2,12]$.

The present study describes a unique isolate of Malassezia isolated from otitis externa of a cat. This clinical isolate was investigated by morphological, biochemical and molecular analyses.

The clinical isolate was obtained from a 6-month-old female Japanese domestic cat which had been deserted. The cat was referred with the chief complaint of ear discharge to the Yasuda Animal Hospital, Nishinomiya, Hyogo, Japan. Physical examination revealed pruritus and discharges from both ears. Microscopic examination disclosed yeast cells in the specimens of ear discharge.

The yeast cells were cultured on modified Dixon agar [9] and Sabouraud's dextrose agar at $37^{\circ} \mathrm{C}$ for 1 week. After 1 week of incubation on modified Dixon agar, the colonies which developed were glistening, smooth and convexed, and had an average diameter of $2 \mathrm{~mm}$ (Fig. 1). The texture of the colonies was soft and viscous. Microscopic examination of the isolate revealed ovoid to globose cells with nar-

\footnotetext{
* Correspondence to: Kano, R., Department of Pathobiology, Nihon University School of Veterinary Medicine, 1866 Kameino, Fujisawa, Kanagawa, 252-8510, Japan.
}

row base (Fig. 2). These yeast cells showed monopolar budding. No growth was obtained on Sabouraud's dextrose agar.

The biological analysis was carried out by the method of Guého et al. [9]. The catalase reaction and DBB reaction were positive. No growth occurred on glucose/peptone agar with $10 \%$ Tween 20 as the sole source of lipid [9]. Growth was observed on glucose/peptone with supplements of $0.1-$ $10 \%$ Tween 40,60 or 80 [9]. Good growth occurred at $37^{\circ} \mathrm{C}$, with a maximum temperature of $40-41^{\circ} \mathrm{C}$.

These results suggested that the clinical isolate was similar to M. sympodialis in biochemical analysis [9].

The yeast cells were collected by scraping colonies from the surface of the agar plate. From these cells, high molecular weight DNAs were obtained as reported previously [12]. These samples were dissolved in TE buffer $(10 \mathrm{mM}$

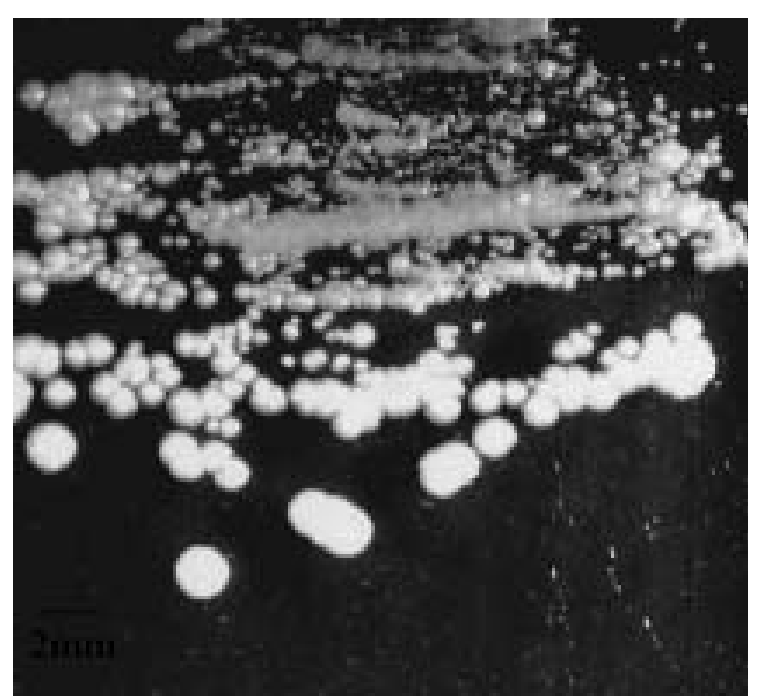

Fig. 1. Clinical isolate cultured on modified Dixon agar at $37^{\circ} \mathrm{C}$ for 1 week 


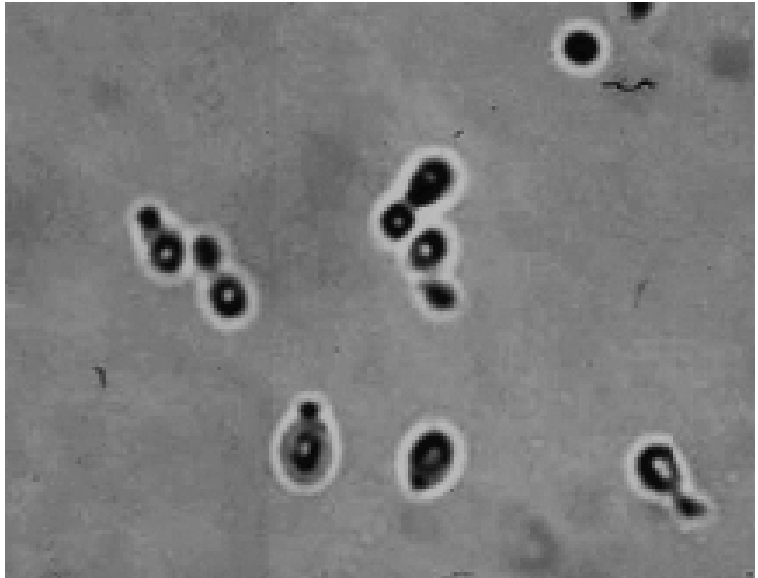

Fig. 2. Microscopic examination of the clinical isolate revealed ovoid to globose cells with narrow base.

Tris-hydroshloride, $\mathrm{pH} 8.0$ and $1 \mathrm{mM}$ EDTA), then used for polymerase chain reaction (PCR) amplification $[1,2,12]$.

The sequences of the degenerate primers for the CHS2 gene were based on the sequences of $M$. pachydermatis (in accession no. AB016719), reported in our previous study: primer Mala S1, 5'-CAC TCG AAC CAT GCA TGG TGT3' (nt. 39-59 in M. pachydermatis CHS2) and primer Mala R1, 5'-CAC CAC AGG CAC CGC CTA C-3' (nt. 517-535 in M. pachydermatis CHS2) $[1,2,12]$. This primer pair amplified the conserved region of the $\mathrm{CHS} 2$ gene in other fungi [3]. PCR amplification of the CHS2 gene was carried out for 35 cycles consisting of template denaturation ( $1 \mathrm{~min}$, at $\left.94^{\circ} \mathrm{C}\right)$, primer annealing $\left(2 \mathrm{~min}\right.$, at $\left.50^{\circ} \mathrm{C}\right)$ and polymerization $\left(3 \mathrm{~min}\right.$, at $\left.72^{\circ} \mathrm{C}\right)$.

The sequences of the degenerate primers for the ITS1 region were the same as those used in our previous study (primer 18SF1, 5'-AGG TTT CCG TAG GTG AAC CT-3' and primer 58SR1, 5'-TTC GCT GCG TTC TTC ATC GA$\left.3^{\prime}\right)$ [13]. PCR amplification of the ITS1 region was carried out for 25 cycles consisting of template denaturation ( $1 \mathrm{~min}$, at $\left.94^{\circ} \mathrm{C}\right)$, primer annealing $\left(15 \mathrm{sec}\right.$, at $\left.60^{\circ} \mathrm{C}\right)$ and polymerization $\left(15 \mathrm{sec}\right.$, at $\left.72^{\circ} \mathrm{C}\right)$.

The sequences of the degenerate primers for $26 \mathrm{~S}$ ribosomal DNA were based on the sequences reported by Fell et al. (primer F63, 5'-GCA TAT CAA TAA GCG GAG GAA AAG-3' and primer LR3, 5'-GGT CCG TGT TTC AAG ACG-3') [6]. PCR amplification of the 26S ribosomal DNA was carried out for 35 cycles consisting of template denaturation $\left(1 \mathrm{~min}\right.$, at $\left.94^{\circ} \mathrm{C}\right)$, primer annealing $\left(2 \mathrm{~min}\right.$, at $\left.55^{\circ} \mathrm{C}\right)$ and polymerization $\left(2 \mathrm{~min}\right.$, at $\left.72^{\circ} \mathrm{C}\right)$.

The PCR products were electrophoresed through $2 \%$ agarose gel and then stained with ethidium bromide.

The sizes of the amplifications with the degenerate primers for $C H S 2$ gene, ITS1 region and 26S ribosomal DNA were $497 \mathrm{bp}, 182 \mathrm{bp}$ and $577 \mathrm{bp}$, respectively.

The cloning and sequencing of the PCR products were performed according to the methods of previous reports [1, $2,12]$. To examine phylogenetic relationships, the nucle-

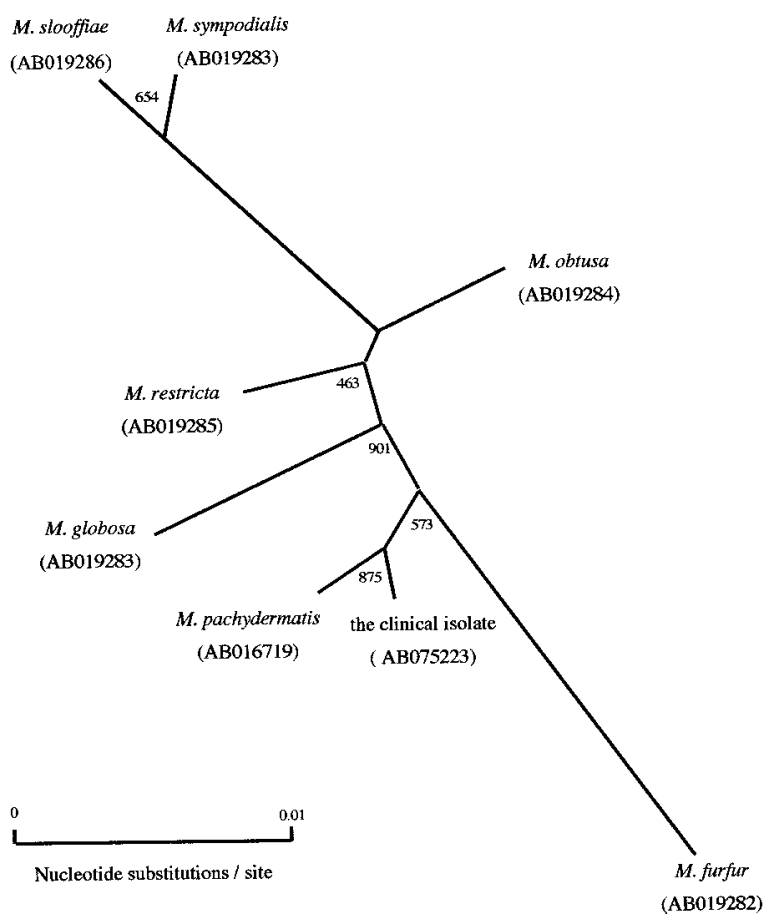

Fig. 3. A tree showing the phylogenetic relationships of $\mathrm{CHS} 2$ gene fragments of the clinical isolate and the seven recognized Malassezia species. The bootstrap values are generated from 1,000 bootstrap trees. The parentheses indicate the GenBank accession nos. of the species.

otide sequences were analyzed by CLUSTAL W multiple sequence alignment programs [18] and a phylogenetic tree was constructed using the TREEVIEW program for displaying phylogenesis [14]. Bootstrap analysis was performed on 1,000 random samples taken from multiple alignments as described by Felsenstein [7], and analyzed by the CLUSTAL W programs.

The nucleotide sequence analysis of the CHS2 gene fragment of the clinical isolate showed $99.2 \%$ similarity to that of $M$. pachydermatis reported previously [12]. The result indicated that the isolate might be $M$. pachydermatis, since intraspecies sequence variation of the CHS2 gene fragment is less than $1 \%$ in Malassezia species [12]. Phylogenetic analysis of the CHS2 gene fragment of the isolate revealed that it was genetically close to $M$. pachydermatis than $M$. sympodialis (Fig. 3).

The nucleotide sequence analysis of the ITS1 region of the clinical isolate showed $70.1 \%$ similarity to that of $M$. sympodialis reported previously [13]. Species identification and strain typing by the ITS1 region are carried out by the method of cluster analysis. Congenerous strains were shown to group into identical clusters and are classified accordingly [13]. In phylogenetic analysis of the ITSI region, the isolate was genetically distinct from the 7 recognized Malassezia species (Fig. 4).

The nucleotide sequence analysis of $26 \mathrm{~S}$ ribosomal DNA 


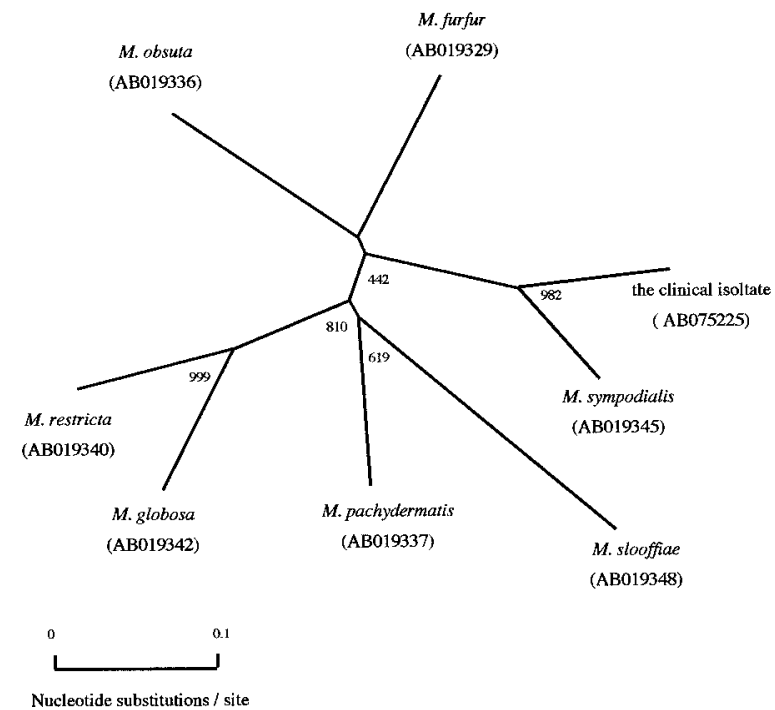

Fig. 4. A tree showing the phylogenetic relationships of ITS1 region of the clinical isolate and the seven recognized Malassezia species. The bootstrap values are generated from 1,000 bootstrap trees. The parentheses indicate the GenBank accession nos. of the species.

of the clinical isolate showed $96.9 \%$ similarity to that of $M$. sympodialis reported previously [6]. Intraspecies sequence variation of $26 \mathrm{~S}$ ribosomal DNA is less than $1 \%[15,17]$. Therefore, the difference between the isolate and M. sympodialis was beyond the intraspecies variation. Furthermore, in phylogenetic analysis of $26 \mathrm{~S}$ ribosomal DNA, the isolate was genetically distinct from the 7 recognized Malassezia species, as in the case of phylogenetic analysis of ITS1 region (Fig. 5).

The molecular analysis of ITS1 region and 26S ribosomal DNA of the clinical isolate suggested that the isolate might be a new species of Malassezia, though biochemical study and $C H S 2$ gene analysis showed that the isolate might be $M$. sympodialis and $M$. pachydermatis, respectively.

\section{REFERENCES}

1. Aizawa, T., Kano, R., Nakamura, Y., Watanabe, S. and Hasegawa, A. 1999. Vet. Microbiol. 70: 67-75.

2. Aizawa, T., Kano, R., Nakamura, Y., Watanabe, S. and Hasegawa, A. 2001. Med. Mycol. 39: 329-334.

3. Chen-Wu, J.L., Zwicker, J., Bowen, A.R. and Robbins, P.W. 1992. Mol. Microbiol. 6: 497-502

4. Crespo, M.J., Abarca, M.L. and Cabanes, F.J. 2000. J. Clin. Microbiol. 38: $1263-1266$

5. Elder, D. 1990. pp. 552-525. In: Lever's Histopathology of the Skin, 8th ed., Lippincott-Raven Publshers, Philadelphia.

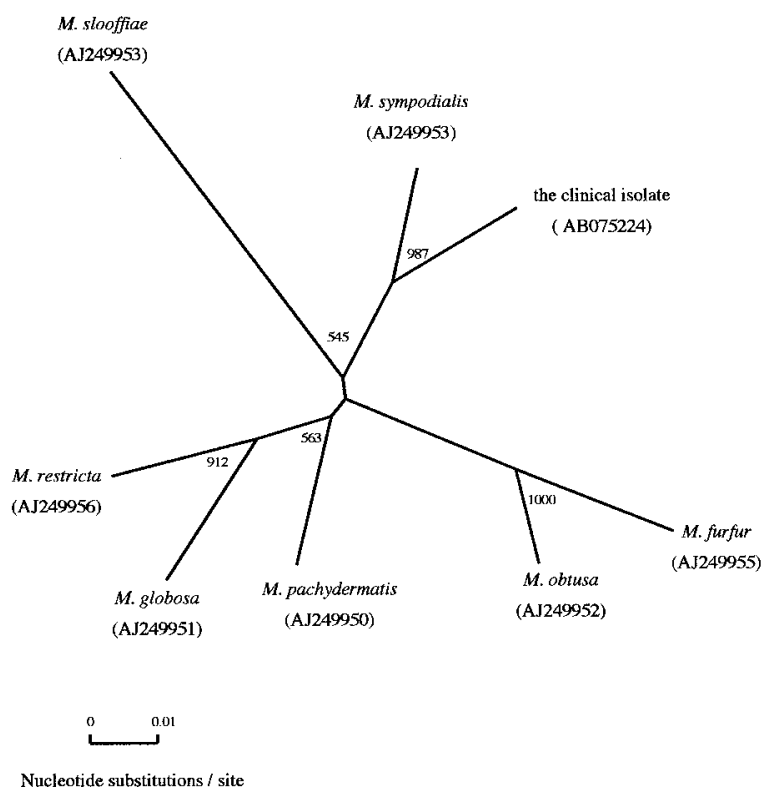

Fig. 5. A tree showing the phylogenetic relationships of 26S ribosomal DNA of the clinical isolate and the seven recognized Malassezia species. The bootstrap values are generated from 1,000 bootstrap trees. The parentheses indicate the GenBank accession nos. of the species.

6. Fell, W.J., Boekhout, T., Fonseca, A., Scorzetti, G. and Statzell-Tallman, A. 2000. Int. J. Syst. Evol. Microbiol. 50: 13511371

7. Felsenstein, J. 1985. Evolution 39: 783-791.

8. Green, C.E. 1998. pp. 549-554. In: Infectious and Diseases of the Dog and Cat, 2nd ed. (Green, C.E. ed.), W.B. Saunders, Philadelphia.

9. Gueho, E., Midgley, G. and Guillot, J. 1996. Antonie van Leeuwenhoek. 69: 337-355.

10. Guillot, J. and Gueho, E. 1995. Antonie van Leeuwenhoek. 67: 297-314.

11. Hagler, A.N. and Ahearn, D.G. 1981. Int. J. Syst. Bacteriol. 31: 204-208.

12. Kano, R., Aizawa, T., Nakamura, Y., Watanabe, S. and Hasegawa, A. 1999. Microbiol. Immunol. 43: 813-815.

13. Makimura, K., Tamura. Y., Kudo, M., Uchida, K., Saito, H. and Yamaguchi, H. 2000. Med. Microbiol. 49: 29-35.

14. Page, R.D.M. 1996. Comput. Appl. Biosci. 12: 357-358.

15. Peterson, S.W. and Kurtzman, C.P. 1991. System. Appl. Microbiol. 14: 124-129.

16. Simmons, R.B. and Gueho, E. 1990. Mycol. Res. 94: 11461149.

17. Sugita, T., Takashima, M., Shinoda, T., Suto, H., Unno, T., Tsudoi, R., Ogawa, H. and Nishikawa, A. 2002. J. Clin. Microbiol. 40: 1363-1367.

18. Thompson, J.D., Higgins, D.G. and Gibson, T. 1994. Nuc. Acid. Res. 22: 4673-4680. 